\title{
Shear Transfer in Bolted Side-Plated Reinforced Concrete Beams
}

\author{
R.K.L. $\mathrm{Su}^{1 *}$, L.Z. $\mathrm{Li}^{2}$, S.H. $\mathrm{Lo}^{3}$
}

${ }^{1 *}$ Associate Professor, Department of Civil Engineering, University of Hong Kong, Pokfulam Road, Hong Kong, China. E-mail: klsu@hku.hk

2 Ph.D. Candidate, Department of Civil Engineering, University of Hong Kong, Pokfulam Road, Hong Kong, China; corresponding author. E-mail: tjlilingzhi@gmail.com

${ }^{3}$ Professor, Department of Civil Engineering, University of Hong Kong, Pokfulam Road, Hong Kong, China. E-mail: hreclsh@hku.hk 


\begin{abstract}
Reinforced concrete (RC) beams strengthened with bolted steel plates on their vertical faces are known as bolted side-plated (BSP) beams. The behaviour and performance of BSP beams are controlled by the arrangement of the steel plates and the interfacial slips caused by the shear deformation of anchor bolts due to shear force transfer. In this study, a nonlinear finite element model validated by available experimental results has been used to investigate the shear stress transfer in BSP beams. The effects of loading arrangements and the stiffnesses of RC beams, steel plates and bolt connections were investigated in detail by a parametric study. The results of this study shed light on the basic understanding of the internal shear transfer mechanism between steel plates and RC beams. A new design approach is also provided to help structural engineers in the determination of the shear transfer profile and the critical bolt shear force in the design of BSP beams.
\end{abstract}

\title{
Keywords:
}

Reinforced concrete beam; Strengthening; Bolted side-plated beam; Transverse slip; Shear transfer; Nonlinear finite element analysis. 


\section{Introduction}

Bolting steel plates to existing reinforced concrete (RC) beams has become a widely accepted retrofitting technique in the past several decades due to its minimal space requirements and convenience of installation. Although bonding steel plates or fibre reinforced polymers (FRPs) by adhesive mortar is the most popular technique, it would lead to premature debonding and peeling failures at the ends of the bonded plates or FRPs [1-3], thus considerable efforts have been made to supress and evaluate this premature failures [4,5]. On the other hand, steel plates attached mechanically by anchor bolts are immune to these adverse effects [6-8]. Although attaching steel plates or channels to beam soffits can effectively increase their flexural strength and stiffness, it may lead to over-reinforcement and a subsequent decrease in the ductility of strengthened beams $[6,9]$. Some researchers thus proposed a bolted side-plating (BSP) technique to anchor steel plates to the side faces of beams by anchor bolts $[7,10]$. The RC beams strengthened using this technique, i.e., the bolted side-plated (BSP) beams, have proven to possess enhanced flexural strength without a significant reduction in ductility [11-13].

Unlike RC beams strengthened with steel plates on the beam soffit, the BSP beams often suffer from plate buckling [14] and bolt slip problems [15-17]. The degree of partial interaction, which controls the behaviour of BSP beams, is affected by both longitudinal and transverse slips, as shown in Fig. 1. The transverse slip $\left(S_{t r}\right)$ is the result of the deformation of anchor bolts under the transverse bolt force $\left(V_{m}\right)$ :

$$
S_{t r}=\frac{V_{m}}{K_{b}}
$$

where $K_{b}=R_{b y} / S_{b y}$ is the bolt stiffness, which can be determined from bolt shear tests; $R_{b y}$ is the yield shear force of the bolt; and $S_{b y}$ is the corresponding yield deformation. Assuming that the bolt behaves in elasto-plastic manner, the bolt stiffness of the shear force-deformation relation in the elastic region is denoted by $K_{b}$. The shear stress transfer $v_{m}$ is defined as the bolt shear force $V_{m}$ divided by the bolt spacing $S_{b}$, i.e., 
$v_{m}=\frac{V_{m}}{S_{b}}=\frac{K_{b}}{S_{b}} S_{t r}=k_{m} S_{t r}$

where $k_{m}=K_{b} / S_{b}$ is the bolt stiffness per unit length. If a uniform bolt spacing is used, $k_{m}$ is a constant along the beam. Theoretically, the shear stress transfer $v_{m}$ and the bolt shear forces $V_{m}$ can be estimated once the transverse slip $S_{t r}$ is measured. However, previous experimental studies [13] have shown that the transverse slip, which usually ranges from 0.01 to $0.5 \mathrm{~mm}$, is hard to measure accurately. Due to the difficulty of accurate measurement and the complex nature of transverse slip and shear transfer, various assumptions are adopted for the transverse slip on the performance of BSP beams. Oehlers et al. [17] established a relationship between the degree of transverse-partialinteraction and the properties of anchor bolts, but assuming a uniform shear distribution at the steelconcrete interface can hardly be justified in many practical applications. Based on this model, Nguyen et al. [18] derived the relationship between longitudinal and transverse partial interactions, but the postulation of a single curvature for both steel plates and RC beams in the calculation of the neutral axis separation violates the transverse-partial-interaction condition. Su and Siu proposed numerical procedures for predicting the nonlinear load-deformation response of bolt groups $[19,20]$ and the longitudinal and transverse slip profiles $[11,16]$ in BSP beams. This approach provides a simple way to determine the transverse slip, despite the fact that the assumption of a linear transverse slip profile has yet to be verified.

In light of the aforementioned limitations concerning various assumptions, a nonlinear finite element analysis (NLFEA) was conducted in this study using the computer program ATENA [21] to investigate the transverse slip and shear transfer behaviour of BSP beams with different beam geometries and under various loading conditions. The test results reported in our companion paper [13] were extracted to validate the finite element model. The validated numerical model was used to conduct a parametric study to evaluate the shear stress transfer of BSP beams. Based on the results, a new design approach for estimating the shear stress transfer profile has been developed. An example is presented to illustrate the effectiveness of the proposed approach in the determination of the shear transfer profile of a BSP beam under realistic loading conditions. 


\section{Numerical modelling}

ATENA is a two-dimensional NLFEA program developed by Cervenka and Cervenka [21] for modelling the nonlinear behaviour of RC members while considering both material and geometric nonlinearities [22]. The main assumptions and methodologies used in the numerical model are briefly presented below.

\subsection{Modelling of concrete}

The concrete in the ATENA model is idealised as a two-dimensional body with a unit thickness. The behaviour of the concrete is simulated by the concrete constitutive model SBETA, which considers (1) the nonlinear behaviour of concrete in compression, including hardening and softening; (2) fracturing of concrete in tension, based on nonlinear fracture mechanics; (3) a biaxial strength failure criterion; (4) the reduction in compressive strength after cracking; and (5) the reduction in shear stiffness after cracking [23]. The constitutive SBETA model is based on the biaxial failure criterion proposed by Kupfer and Gerstle [24] and the equivalent uniaxial stress-strain curve proposed by Darwin and Pecknold [25]. The effective concrete tensile and compressive strengths were determined as functions of the current stress states according to the Kupfer failure criterion [24]. The effective principal stresses were determined from the equivalent uniaxial strains according to the modified equivalent constitutive curve, which considers four states (see Fig. 2): (1) concrete in tension before cracking is idealised as a linearly elastic material, (2) concrete after cracking is considered using a fictitious crack model based on the exponential crack opening model and fracture energy [26] (see Eq. (3)), (3) concrete in compression before the peak stress is described by CEB-FIP Model Code 90 [27] (see Eq. (4)), and (4) concrete after the peak stress is described by a fictitious compression plane model [28] (see Eq. (5)).

$$
\frac{\sigma_{c n}}{f_{c}^{e f}}=\left[1+\left(\frac{3 w_{c}}{w_{c r}}\right)^{3}\right] \exp \left(-6.93 \frac{w_{c}}{w_{c r}}\right)-\frac{10 w_{c}}{w_{c r}} \exp (-6.93), \quad w_{c r}=5.14 \frac{G_{f}}{f_{t}^{e f}}
$$


$\sigma_{c}^{e f}=\frac{\frac{E_{0}}{E_{c c}}-\left(\frac{\varepsilon_{c}^{e q}}{\varepsilon_{c 0}}\right)^{2}}{1+\left(\frac{E_{0}}{E_{c c}}-2\right)\left(\frac{\varepsilon_{c}^{e q}}{\varepsilon_{c 0}}\right)} f_{c}^{e f}$

$\varepsilon_{c d}=\varepsilon_{c 0}+\frac{w_{c d}}{L_{c d}}$

To represent the material properties of the locally mixed concrete used in the experiment, the compressive strength and elastic modulus were chosen as the values obtained in the experiment, and the strain at peak stress and the plastic displacement for the fictitious compression plane model were taken as the following [23]:

$\left\{\begin{array}{l}\varepsilon_{c 0}=-3.46\left|f_{c u}\right|^{0.75} / E_{0} \\ w_{c d}=-6 \mathrm{~mm}\end{array}\right.$

\subsection{Modelling of reinforcement and steel plates}

A bilinear elastic material model with hardening was chosen to represent reinforcement. The transverse reinforcement was modelled by adding a smeared reinforcement layer to the concrete layer. The longitudinal reinforcement was modelled in ATENA using the discrete bar element CCBarWithBond [22] to consider the bond-slip effect according to the CEB-FIP Model Code 90 [27].

The steel plates were idealised as a plane stress layer and the steel material was simulated using the bilinear steel Von Mises model, which considers a biaxial failure law and a bilinear stress-strain curve, taking into account both the elastic state and the hardening of the steel.

\subsection{Modelling of bolt connections}

In the NLFEA, steel plates were not directly connected to the RC beam as interfacial slips exist between the plate and RC beam [10]. In this study, bolt connections were modelled by discrete bolt elements using the bilinear Von Mises model as shown in Fig. 3(a). Two types of element were used to model a single bolt connection: (1) the four internal triangular elements with a high stiffness were employed to simulate the possible compressive deformation of the bolt shaft, and (2) the four external 
quadrilateral elements with a lower stiffness were utilised to simulate the shear deformation of the bolt shaft. The central node and outer nodes of the bolt elements were connected to steel plate layer and concrete layer respectively as illustrated in Fig.3(b). A simple NLFEA model using the aforementioned discrete bolt elements was constructed to simulate the experimentally results from bolt shear tests. The material properties of the bolt elements were calibrated against the experimental results [13]. A comparison of the predicted and measured load-slip curves of a bolt connection is shown in Fig. 3(c). Good agreement between the test and numerical results is observed. The calibrated bolt elements were used in the subsequent finite element models of BSP beams.

\subsection{Finite element meshes and load steps}

Both the concrete and smeared transverse reinforcement layers were composed of 4-node isoparametric plane stress elements with an element size of $12.5 \mathrm{~mm}$. Their meshes were identical and connected to each other at every node so that perfect bonding could be assumed. The discrete longitudinal reinforcement was modelled by 2-node bar elements, and the bond-slip effect was taken into account by introducing the bond-slip relation into the displacement discrepancy between the bar nodes and the corresponding concrete layer nodes. The steel plates were modelled by a layer of 4-node isoparametric plane stress elements with an element size of $12.5 \mathrm{~mm}$. The node coordinates of the concrete and steel plate layers were designed so that the nodes located at the anchor bolts were exactly coincident with the external and central nodes of the bolt elements. The hinge and rollers at the supports and the loading points were simulated by 4-node isoparametric plane-stress rigid plates to prevent high stress concentration. The finite element meshes of the specimen P100B450 [13] are shown in Fig. 4, in which only half of the meshing is illustrated owing to the symmetry of the geometry and loading.

Monotonic displacements were induced at the two loading points, and the modified NewtonRaphson method was used to determine the complete load-deflection curve, including the post-peak descending branch. 


\section{Validation of the numerical model}

\subsection{A brief introduction to the experimental study}

In the previous experimental study, seven RC beams were tested under four-point bending [13] to investigate the behaviour of BSP beams. The transverse slip profiles and load-deflection curves of four BSP beams with the same RC geometry for different bolt-plate arrangements were used to validate the numerical model.

These four BSP beams and the control beam were of length $4000 \mathrm{~mm}$ and cross section $225 \mathrm{~mm} \times 350 \mathrm{~mm}$. 2T10 compressive reinforcement, R10-100 transverse reinforcement and 6T16 tensile reinforcement with a tensile steel ratio of $1.77 \%$ were used. The material properties of the reinforcement and steel plates are listed in Table 1.

Fig. 5 shows the reinforcement and strengthening arrangements of the specimens. HIT-RE 500 adhesive and 10-mm-diameter HAS-E anchor bolts [29] were used to attach the steel plates to the vertical faces of the beam. Steel plates with $6 \mathrm{~mm}$ thickness but two different depths, $D_{p}=100 \mathrm{~mm}$ (i.e., shallow plates for $D_{p} / D_{c}=100 / 350<1 / 3$, where $D_{c}$ is the beam depth) and $D_{p}=250 \mathrm{~mm}$ (i.e., deep plates for $D_{p} / D_{c}=250 / 350>1 / 2$ ) were chosen to yield distinct strengthening effects. Buckling restraint devices were introduced to alleviate the plate buckling that might occur in the compressive regions of the deep steel plates. Table 2 summarises the specimen names, concrete strengths, and design parameters of the steel plates, anchor bolts and buckling restraint arrangements, as well as the recorded peak loads $F_{p}$ of these specimens.

Four-point bending tests were conducted on specimens with clear spans of $L=3600 \mathrm{~mm}$ and pure bending zones of $1200 \mathrm{~mm}$. A displacement-controlled loading process was designed to investigate the load-deflection behaviour, especially in the post-peak region. The loading rate was chosen as $0.01 \mathrm{~mm} / \mathrm{sec}$ up to $50 \%$ of the theoretical peak load and was then increased to $0.02 \mathrm{~mm} / \mathrm{sec}$ until the post-peak load decreased to $80 \%$ of the actual peak load and the test was terminated.

The shear force-slip response of the anchor bolts was tested using three specially designed samples. The recorded bolt shear force-slip curve is shown in Fig. 3(b). 
A new slip measuring device was tailor-made to precisely measure the longitudinal and the transverse slips as shown in Fig. 6. This device was composed of two sets: Set A was embedded into the RC beam, and Set B was fixed onto and moved with the steel plate when relative slips occurred. Three LVDTs were installed on Set A, one was in the transverse direction with the probe tip in contact with the lower edge of the steel plate, and the other two were in the longitudinal direction with the probe tips pointing at the upper and lower sides of Set B. Hence, if slips occurred, the first LVDT measured the transverse slip, and the other two recorded the longitudinal slips. Therefore, three LVDTs are needed for the slip measuring of a single position. A total of 12 sets were fabricated to precisely measure the distribution of slips along the beam span.

The experimental results showed that for the BSP beams with the same size of steel plates, the transverse slip increased with the bolt spacing when the load level was less than 0.75 , but afterwards it increased drastically and was controlled by the concrete strength. This enormous increase was caused by the rapid deterioration of the flexural stiffness of the RC beam after the formation of plastic hinges. For the BSP beams have the same bolt spacing, the transverse slips increase significantly with the increase in plate depth.

\subsection{Comparison of the test and numerical results}

The overall load-deflection curves derived from the numerical and experimental studies are compared in Fig. 7. The numerical results generally capture the full range behaviour of all the specimens with shallow (P100B300 and P100B450) and deep steel plates (P250B300R and P250B450R) in the tests, except for a slight overestimation of both stiffness and peak load. This outcome may be due to the difference in concrete strength between the RC beams and concrete cubes and the inevitable plate buckling that occurred despite the use of buckling restraint measures. It should be noted that there is a small overestimation of the peak load; the values are off by only $2.0 \%, 0.5 \%$, 1.7\% and 3.7\% in specimens P100B300, P100B450, P250B300R and P250B450R, respectively.

The transverse slip profiles for specimens $\mathrm{P} 100 \mathrm{~B} 300$ and $\mathrm{P} 250 \mathrm{~B} 300 \mathrm{R}$ at two load levels $\left(F / F_{p}=\right.$ 0.25 and 0.75 , where $F$ is the total applied load) are compared in Fig. 8. The numerical and 
experimental profiles are in good agreement with each other. The numerical and experimental transverse slip at the loading points are listed in Table 3 for all specimens at four different load levels $\left(F / F_{p}=0.25,0.50,0.75\right.$ and 1.00$)$. The numerical predictions agree very well with the experimental transverse slip for specimens P100B300 and P100B450, and the average numerical-to-experimental slip ratios at the loading point are 1.13 and 0.93 , respectively. The predicted slips for specimens P250B300R and P250B450R are also acceptable, despite some overestimation, with average numerical-to-experimental slip ratios of 1.10 and 1.28 , respectively. The discrepancy may be due to the buckling that occurred in the deep steel plates, which reduced their flexural stiffness and hence reduced the transverse slip measured in the tests.

\section{Parametric study}

\subsection{A brief introduction to the numerical models}

Fig. 9(a) shows the reference BSP beam used in the parametric study, which has the same geometry as specimen P100B300. The flexural stiffness of the RC beam and the steel plates and the stiffness of the bolt connections of the reference beam are as follows:

$$
(E I)_{c}{ }^{\prime}=8000 \mathrm{kM} \cdot \mathrm{m}^{2}
$$

$$
(E I)_{p}{ }^{\prime}=220 \mathrm{kM} \cdot \mathrm{m}^{2}
$$

$k_{m}{ }^{\prime}=370 \mathrm{kN} / \mathrm{m}^{2}$

Six basic loading cases, illustrated in Fig. 9, were considered in the parametric study, including (a) a midspan point load, (b) an asymmetrically arranged point load, (c) two symmetrically arranged point loads, (d) a uniformly distributed load (UDL), (e) a trapezoidal distributed load and (f) a triangularly distributed load. The influences of the different load levels $\left(F / F_{p}\right)$, the flexural stiffness of the RC beam $(E I)_{c}$, and the plate-RC and bolt-RC stiffness ratios $\left(\beta_{p}=(E I)_{p} /(E I)_{c}\right.$ and $\left.\beta_{m}=k_{m} /(E I)_{c}\right)$ on the shear transfer profile were investigated. 
By varying the location of the applied point load, the shear stress transfers at specific locations, such as at the left support $\left(v_{m, L S}\right)$, the right support $\left(v_{m, R S}\right)$ and the loading point, for concentrated load cases $\left(v_{m, F}\right)$, were obtained. For the distributed load cases, $v_{m, F}$ is the shear stress transfer at the midspan.

The half bandwidth of the shear transfer profile $w$ is a distance measured from the location of $v_{m, F}$ to the first intersection of the shear transfer profile and the beam axis, as shown in Figs. 10 and 11 . It reflects the extent of the influence zone of the transverse loads and the interaction between the adjacent loads.

The half bandwidth $(w)$ together with the shear transfers at the midspan $\left(v_{m, F}\right)$ and the supportmidspan shear transfer ratio $\left(v_{m, L S} / v_{m, F}\right.$ and $\left.v_{m, R S} / v_{m, F}\right)$ is useful for defining the entire shear transfer profile of some basic loading cases.

\subsection{Shear transfer profiles under different loading arrangements}

By varying the position of the point loads acting on the reference beam, the influence of the applied load location on the shear transfer profile was investigated. Fig. 10 shows the typical variations of shear transfer profiles for both the asymmetrically arranged single point load and symmetrically arranged two-point load cases. For the single-point-load case, when the point load was close to the left support $\left(x_{F} / L=1 / 6\right)$, the negative shear transfer at its right side was negligible, but was concentrated at its left side with a very steep slope $\left(v_{m, L S}>v_{m, F}>v_{m, R S}\right)$. As the load moved toward the midspan, the positive shear transfer and the negative shear transfer on its right side increased gradually, while those on its left side decreased and acquired a gentler slope (the ratio $v_{m, L S} / v_{m, F}$ decreased, whereas $v_{m, F}$ and the ratio $v_{m, L S} / v_{m, F}$ increased). As shown in Fig. 10(b), when two point loads were relatively far apart and close to the supports $\left(x_{F} / L=1 / 12\right)$, the positive shear transfer from the RC beam to the steel plates was resisted mainly by the negative shear transfer at the supports, and the shear transfers at the supports were more critical than those under the point loads $\left(v_{m, L S}=v_{m, R S}>v_{m, F}\right)$. As the two loads got closer to each other and eventually became a single load $\left(x_{F} / L=1 / 2\right)$, the positive shear transfer near the midspan increased and the shear transfer $v_{m, F}$ increased gradually. Meanwhile, the negative shear transfers at the supports and the slopes of the negative shear transfers 
between the loads and the supports became more and more gentle $\left(v_{m, L S} / v_{m, F}=v_{m, R S} / v_{m, F}\right.$ decreased). In other words, the magnitude of the shear transfer $\left(v_{m, F}\right)$ and the shear transfer ratios $\left(v_{m, L S} / v_{m, F}\right.$ and $v_{m, R S} / v_{m, F}$ ) were highly dependent on the locations of the external loads. Furthermore, the half bandwidth (w) also varied significantly as the locations of the external loads changed. The shear transfer ratios $\left(v_{m, L S} / v_{m, F}\right.$ and $\left.v_{m, R S} / v_{m, F}\right)$ of the shallow plates and the dimensionless half bandwidth $w / L$ of the deep and shallow plates under various loading cases are presented in Table 4.

The applicability of the superposition principle to the evaluation of the transverse slips in BSP beams under the working load conditions $\left(F / F_{p}<0.5\right)$ with weak material non-linearity is studied in this section. The shear transfer profile under a point load at the left trisectional point was added to that under a point load at the right trisectional point, and the resultant shear profile was compared with the shear transfer profile under two point loads at trisectional points (when $F / F_{p}=0.5$ ). The comparison, shown in Fig. 11(a), indicates that the two profiles are very similar. When five point loads with a uniform spacing were applied, the profile obtained from the superposition principle was very close to that obtained from the NLFEA under a UDL (when $F / F_{p}=0.5$ ), as shown in Fig. 11(b). Therefore, it is evident that the shear transfer profile of complicated load arrangements can be estimated by superimposing the shear transfer profiles from the basic load cases.

\subsection{Shear transfers under different load levels and beam geometries}

The magnitudes of the applied loads ( $F$ or $q$ in Fig. 9) were varied to study the influence of load level $F / F_{p}$ on the shear transfer $v_{m, F}$. For brevity, $v_{m, F}$ was divided by the peak total applied load $F_{p}$ and the span length $L$ to obtain a dimensionless shear transfer ratio $\xi_{F p}$ as follows:

$$
\xi_{F p}=v_{m, F} /\left(\frac{F_{p}}{L}\right)=\frac{V_{m, F}}{F_{p}} \cdot \frac{L}{S_{b}}
$$

The stiffness of the RC beam $(E I)_{c}$, the steel plates $(E I)_{p}$ and the bolt connection $k_{m}$ were also varied to study their effects on $v_{m, F}$, which can be quantified by the shear transfer factor $\zeta$ defined as follows:

$$
\zeta=\frac{\xi_{F p}}{\xi_{F p}{ }^{\prime}}=\frac{V_{m, F}}{V_{m, F}{ }^{\prime}} \cdot \frac{F_{p}{ }^{\prime}}{F_{p}} \cdot \frac{S_{p}{ }^{\prime}}{S_{p}}
$$


The shear transfer factors due to the changes in $(E I)_{c},(E I)_{p}$ and $k_{m}$ are denoted by $\zeta_{E I c}, \zeta_{E I p}$ and $\zeta_{k m}$, respectively. Combining the dimensionless shear transfer ratio $\xi_{F p}$ and the shear transfer factors $\left(\zeta_{E I c}\right.$, $\zeta_{E I p}$ and $\left.\zeta_{k m}\right)$, the shear stress transfer $v_{m, F}$ can be evaluated as follows:

$$
v_{m, F}=\zeta_{E I c} \cdot \zeta_{E I p} \cdot \zeta_{k m} \cdot \xi_{F p} \cdot \frac{F_{p}}{L}
$$

The dimensionless shear transfer ratios $\xi_{F p}$ at different load levels $F / F_{p}$ are depicted in Fig. 12(a). Under the load level $F / F_{p}<0.75$, the square root of the dimensionless shear transfer ratio $\left(\xi_{F p}{ }^{1 / 2}\right)$, in general, increases linearly with the load level $\left(F / F_{p}\right)$. However, when $F / F_{p}>0.75$, the results from the NLFEA revealed that serious degradation of concrete occurs and the steel plates take up more of the loading. As a result, the dimensionless shear transfer ratio increases rapidly. Because the shear transfer $v_{m, F}$ increases dramatically when the load level approaches unity, a load level of $F / F_{p}<0.75$ should be adopted for the design of BSP beams. When $F / F_{p}<0.75$, the dimensionless shear transfer ratios for all single point load cases and all distributed load cases can be estimated as follows:

$\xi_{F p}= \begin{cases}{\left[0.65 \times\left(F / F_{p}\right)\right]^{2}} & \text { under a point load } \\ {\left[0.30 \times\left(F / F_{p}\right)\right]^{2}} & \text { under a distributed load }\end{cases}$

The variations in the shear transfer factors $\zeta_{E I c}, \zeta_{E I p}$ and $\zeta_{k m}$ for the corresponding stiffness $(E I)_{c}$, $(E)_{p}$ and $k_{m}$ (under a load level $F / F_{p}<0.75$ ) are plotted in Fig. 12(b). After some trials of different curve-fitting functions, it was found that the variation of the shear transfer factors could be approximated as follows:

$\zeta_{E I c}=\left\{1-0.13 \times \log \left[(E I)_{c} /(E I)_{c}{ }^{\prime}\right]\right\}^{16}$, where $(E I)_{c}{ }^{\prime}=8000 \mathrm{kM} \cdot \mathrm{m}^{2}$

$\zeta_{E I p}=\left\{1+0.19 \times \log \left[(E I)_{p} /(E I)_{p}{ }^{\prime}\right]\right\}^{8}, \quad$ where $(E I)_{p}{ }^{\prime}=220 \mathrm{kM} \cdot \mathrm{m}^{2}$

$\zeta_{k m}=\left[\frac{1.8}{1+0.8 \times 10^{-\log \left(k_{m} / k_{m}{ }^{\prime}\right)}}\right]^{\frac{1}{3}}=\left[\frac{1.8}{1+0.8 \times\left(k_{m}{ }^{\prime} / k_{m}\right)}\right]^{\frac{1}{3}}$, where $k_{m}{ }^{\prime}=370 \mathrm{kN} / \mathrm{m}^{2}$ 
It can be observed from the figures that as the stiffness $\left((E I)_{c},(E I)_{p}\right.$ or $\left.k_{m}\right)$ is reduced to $1 \%$ or increased by 100 times, the variation in $\zeta_{\text {EIC }}{ }^{1 / 16}, \zeta_{\text {EIp }}{ }^{1 / 8}$ and $\zeta_{k m}{ }^{3}$ are all within the range of 0 to 2 . However, the rates of change of the various shear transfer factors $\left(\zeta_{E I c}, \zeta_{E I p}\right.$ and $\left.\zeta_{k m}\right)$ are very different, due to the differences in the magnitudes of the exponents $(1 / 16,1 / 8$ and 3). Because the shear transfer $v_{m, F}$ decreases (or increases) dramatically as $(E I)_{c}\left(\right.$ or $\left.(E I)_{p}\right)$ increases, an excessive plate-RC stiffness ratio $\left(\beta_{p}=(E I)_{p} /(E I)_{c}\right)$ should be avoided in the design of BSP beams.

\subsection{Half bandwidths under different load levels and beam geometries}

The shear transfer profiles of BSP beams subjected to a single point load at the midspan for different $F / F_{p}$, $(E I)_{c}, \beta_{p}$ and $\beta_{m}$ were evaluated. The computed shear transfer profiles were normalised by $v_{m, F}$ so that the normalised shear transfer stress at the midspan was equal to one. Fig. 13 presents the normalised shear transfer profiles. As shown in Figs. 13(a) and (b), the shapes of the normalised profiles for different $F / F_{p}$ and different $(E I)_{c}$ were very similar, and the half bandwidth $w$ remained almost unchanged. However, it is evident in Figs. 13(c) and (d) that $w$ increased with increasing $\beta_{p}$ and decreasing $\beta_{m}$. The results further revealed that $w$ is a constant when the plate-bolt stiffness ratio remains unchanged, i.e., $(E I)_{p} / k_{m}=\beta_{p} / \beta_{m}=C_{1}$, where $C_{1}$ is a constant.

In other words, the half bandwidth $w$ is independent of the load level $F / F_{p}$ and the stiffness of the RC beam $(E I)_{c}$ but is controlled by the plate-bolt stiffness ratio $\beta_{p} / \beta_{m}$. The variation in the relative half bandwidth $(w / L)$ as $\left(\beta_{p} / \beta_{m}\right)^{1 / 4}$ is plotted in Fig. 14 and can be expressed by the following approximately linear relationship:

$$
\frac{w}{L}=0.07 \times\left(\frac{\beta_{p}}{\beta_{m}}\right)^{\frac{1}{4}}+0.10
$$

Therefore, for a BSP beam under three-point bending, $w$ can be obtained using Eq. (17). For a proper strengthening design, the number of anchor bolts used should be proportional to the area of the steel plates so that yielding of the steel plates happens prior to failure of the anchor bolts. Thus 
$\frac{1}{\gamma_{b}} n_{b} R_{b y}=f_{y p} A_{p}$

where $\gamma_{b}$ is a partial safety factor, $n_{b}$ is the number of anchor bolts in a shear span, and $f_{y p}$ and $A_{p}$ are the yield strength and cross-sectional area, respectively, of the steel plates.

As Eq. (19) shows, the ratio of the axial plate stiffness to the bolt connection stiffness, $\beta_{a} / \beta_{m}$, is a constant.

$$
\frac{\beta_{a}}{\beta_{m}}=(E A)_{p} / k_{m}=\left(E \cdot \frac{n_{b} R_{b y}}{\gamma_{b} f_{y p}}\right) /\left(\frac{R_{b y}}{S_{b y} S_{b}}\right)=\left(\frac{L S_{b y} E}{2 \gamma_{b} f_{y p}}\right)=C_{2}
$$

where $n_{b} S_{b}=L / 2$ is the length of a shear span. However, the flexural stiffness ratio $\beta_{p} / \beta_{m}$, which controls the length of the half bandwidth $w$, is not a constant but rather increases with increasing plate depth $D_{p}$ :

$$
\frac{\beta_{p}}{\beta_{m}}=(E I)_{p} / k_{m}=i_{p}{ }^{2} \cdot(E A)_{p} / k_{m}=\left(\frac{L S_{b y} E}{24 \gamma_{b} f_{y p}}\right) \cdot D_{p}{ }^{2}=\frac{C_{2}}{12} \cdot D_{p}{ }^{2}
$$

where $i_{p}$ is the radius of gyration of the steel plates. Substituting Eq. (20) into Eq. (17) yields the following expression for the half bandwidth:

$$
\frac{w}{L}=0.038 C_{2}^{\frac{1}{4}} \cdot D_{p}^{\frac{1}{2}}+0.10
$$

Eq. (21) demonstrates that the half bandwidth $w$ can be determined once the strengthening layout is known. It is also evident that $w$ varies linearly with $D_{p}{ }^{1 / 2}$ and thus is not very sensitive to changes in the plate depth. Hence, in real strengthening design, BSP beams can be roughly categorised into two types with respect to the plate depth $\left(D_{p}\right)$ : shallow plate $\left(D_{p}<D_{c} / 3\right)$ and deep plate $\left(D_{p}>D_{c} / 2\right)$ cases. Two single values ( $w / L=0.155$ and 0.250 , respectively) can be chosen for them. The dimensionless half bandwidths $w / L$ of BSP beams for shallow and deep plate cases for all basic load cases are listed in Table 4.

4.5. Support-midspan shear transfer ratios for different load levels and beam geometries 
Figs. 13(a) and (b) show that the variations in the support-midspan shear transfer ratios $\left(v_{m, L S} / \nu_{m, F}\right.$ and $\left.v_{m, R S} / v_{m, F}\right)$ for different load levels $\left(F / F_{p}\right)$ and RC stiffnesses $(E I)_{c}$ are relatively small. However, it is evident from Figs. 13(c) and (d) that the ratios vary significantly with increasing $\beta_{p}$ and decreasing $\beta_{m}$

Although curve-fitting results similar to Eq. (17) can be obtained for the support-midspan shear transfer ratios $\left(v_{m, L S} / v_{m, F}\right.$ or $\left.v_{m, R S} / v_{m, F}\right)$, they are omitted for brevity. This approach is used because their variations in $\beta_{p} / \beta_{m}$ and $D_{p}$ are similar to that of the half bandwidth $(w / L)$. The ratios for a BSP beam with shallow steel plates for different load cases are listed in Table 4. For deep steel plates, these ratios can be slightly modified by multiplying them by the ratio of the $w$ values for deep and shallow plates. For instance, the ratio $v_{m, L S} / v_{m, F}$ for deep plates under a UDL can be computed as 2.70 $=2.43 \times(0.400 / 0.360)$, where 2.43 is the ratio $v_{m, L S} / v_{m, F}$ for shallow plates and $0.400 / 0.360$ is the ratio of $w$ values for deep and shallow plates.

\subsection{Evaluation of shear transfer and bolt shear force in BSP beams}

The procedure for evaluation of the shear transfer profile and bolt shear forces in a BSP beam is described in this section. When the geometry of a BSP beam, its material properties and the external loads are defined, the values of parameters such as $F,(E I)_{c},(E I)_{p}$ and $k_{m}$, as well as those of the stiffness ratios $\left((E I)_{c} /(E I)_{c}{ }^{\prime},(E I)_{p} /(E I)_{p}{ }^{\prime}\right.$ and $\left.k_{m} / k_{m}{ }^{\prime}\right)$, can be determined. From the sectional analysis and the loading arrangement, the peak load $\left(F_{p}\right)$ and hence the load level $\left(F / F_{p}\right)$ can be evaluated. Using Eq. (13), the value of the dimensionless shear transfer ratio $\xi_{F p}$, which is a function of $F / F_{p}$, can then be obtained. Employing Eqs. (14) to (16), the values of the shear transfer factors $\zeta_{E I c}, \zeta_{E I p}$ and $\zeta_{k m}$ can be computed. The magnitude of the shear transfer $\left(v_{m, F}\right)$ at the loading points or the midspan of the beam can then be determined using Eq. (12).

From Table 4, the support-midspan shear transfer ratios $\left(v_{m, L S} / v_{m, F}\right.$ and $\left.v_{m, R S} / v_{m, F}\right)$ and therefore the shear transfers at the supports can be evaluated. The dimensionless half bandwidth $(w / L)$, as shown in Table 4, can be used to locate the point of zero shear transfer. By combining the shear stress 
transfers at specific locations using a piecewise polyline, the entire shear transfer profile can be determined.

The shear transfer profile of a complicated loading arrangement can be determined by superimposing the shear transfer profiles of the individual basic load cases. Using Eqs. (1) and (2), the bolt shear forces can be derived from the shear stress transfer profile.

\subsection{Example}

Consider a simply supported RC beam under a point load $\left(F_{1}=250 \mathrm{kN}\right)$ and a UDL $\left(q_{2}=120 \mathrm{kN} / \mathrm{m}\right)$, as shown in Fig. 15 . The clear span is $4200 \mathrm{~mm}$ and the cross section is $300 \mathrm{~mm} \times$ $600 \mathrm{~mm}$. Compression reinforcement of 3T10 and tension reinforcement of 4T25 are employed. Two steel plates of $6 \mathrm{~mm} \times 200 \mathrm{~mm}$ are bolted to the side faces of the beam by a row of anchor bolts at a spacing of $350 \mathrm{~mm}$. The material properties are as follows:

$$
\begin{cases}f_{c}=30 \mathrm{MPa}, & E_{c}=23 \mathrm{GPa} \\ f_{y}=460 \mathrm{MPa}, & E_{s}=211 \mathrm{GPa} \\ f_{y p}=355 \mathrm{MPa}, & E_{p}=210 \mathrm{GPa} \\ R_{b y}=58 \mathrm{kN}, & S_{b y}=0.5 \mathrm{~mm}\end{cases}
$$

The stiffness of the RC beam, the steel plates and the bolt connection can be computed based on the geometry of the beam and the material properties, which are given by:

$$
\left\{\begin{array}{l}
(E I)_{c}=31400 \mathrm{kN} \cdot \mathrm{m}^{2} \\
(E I)_{p}=168 \mathrm{kN} \cdot \mathrm{m}^{2} \\
k_{m}=320 \mathrm{kN} / \mathrm{m}^{2}
\end{array}\right.
$$

Substituting the stiffnesses into Eqs. (14) (16) yields the following shear transfer factors:

$$
\left\{\begin{array}{l}
\zeta_{\text {EIc }}=[1-0.13 \times \log (31400 / 80000)]^{16}=0.043 \\
\zeta_{\text {EIp }}=[1+0.19 \times \log (168 / 220)]^{8}=13.90 \\
\zeta_{k m}=\left[\frac{1.8}{1+0.8 \times(370 / 320)}\right]^{\frac{1}{3}}=0.980
\end{array}\right.
$$


The ultimate bending moment, computed from a moment-curvature analysis, is $M_{u}=576 \mathrm{kN} \cdot \mathrm{m}$. Thus, the peak loads when only the point load $\left(F_{1}\right)$ or the UDL $\left(q_{2}\right)$ is imposed can be obtained as follows:

$$
\left\{\begin{array}{l}
F_{p, 1}=\frac{M_{u}}{L_{1}}=\frac{576}{1.05}=549 \mathrm{kN} \\
F_{p, 2}=\frac{M_{u}}{L^{2} / 8} L=\frac{576 \times 8}{4.2}=1101 \mathrm{kN}
\end{array}\right.
$$

Substituting the peak forces $\left(F_{p 1}\right.$ and $\left.F_{p 2}\right)$ into Eq. (13) yields the following values:

$$
\left\{\begin{array}{l}
\xi_{F p, 1}=\left(0.65 \times \frac{250}{549}\right)^{2}=0.087 \\
\xi_{F p, 2}=\left(0.30 \times \frac{120 \times 4.2}{1101}\right)^{2}=0.019
\end{array}\right.
$$

Substituting Eqs. (24) and (26) into Eq. (12) yields the following values for shear transfer in the midspan:

$$
\left\{\begin{array}{l}
v_{m, F, 1}=0.043 \times 13.9 \times 0.98 \times 0.087 \times \frac{549}{4.2}=6.76 \mathrm{kN} / \mathrm{m} \\
v_{m, F, 2}=0.043 \times 13.9 \times 0.98 \times 0.019 \times \frac{1101}{4.2}=2.93 \mathrm{kN} / \mathrm{m}
\end{array}\right.
$$

Multiplying the midspan shear transfer by the support-midspan shear transfer ratios in Table 4 yields the following shear transfers at the supports ( $x=0 \mathrm{~mm}$ and $4200 \mathrm{~mm}$ ):

$$
\left\{\begin{array}{l}
v_{m, L S, 1}=1.04 \times 6.76=7.0 \mathrm{kN} / \mathrm{m} \\
v_{m, R S, 1}=0.32 \times 6.76=2.2 \mathrm{kN} / \mathrm{m} \\
v_{m, L S, 2}=v_{m, R S, 2}=2.43 \times 2.93=7.1 \mathrm{kN} / \mathrm{m}
\end{array}\right.
$$

By superimposing the shear stress transfers for both load cases, the shear transfer as well as the bolt shear force can be evaluated as follows:

$$
\left\{\begin{array}{l}
v_{m, L S}=7.0+7.1=14.2 \mathrm{kN} / \mathrm{m} \\
v_{m, R S}=2.2+7.1=9.3 \mathrm{kN} / \mathrm{m} \\
v_{m, F}=6.8+2.9=9.7 \mathrm{kN} / \mathrm{m}
\end{array}\right.
$$


$\left\{\begin{array}{l}V_{m, L S}=14.2 \times 0.35=5.0 \mathrm{kN} \\ V_{m, R S}=9.3 \times 0.35=3.3 \mathrm{kN} \\ V_{m, F}=9.7 \times 0.35=3.4 \mathrm{kN}\end{array}\right.$

The maximum shear transfer and bolt shear force are found to occur at the left support. Their magnitudes are $14.2 \mathrm{kN} / \mathrm{m}$ and $5.0 \mathrm{kN}$, respectively.

The dimensionless half bandwidths $(w / L)$ for $F_{1}$ and $q_{2}$ are 0.133 and 0.360 (see Table 4). Because the negative shear transfer near the left support is influenced by both $F_{1}$ and $q_{2}$ and that near the right support is mainly controlled by $q_{2}$, the locations where shear transfer is zero can be approximately computed as follows:

$\left\{\begin{array}{l}x_{L}=4200 \times \frac{(0.5-0.360)+(0.25-0.133)}{2}=540 \mathrm{~mm} \\ x_{R}=4200 \times(0.5+0.360)=3610 \mathrm{~mm}\end{array}\right.$

The shear transfer profile is found by connecting the shear transfers at specific locations using a piecewise polyline:

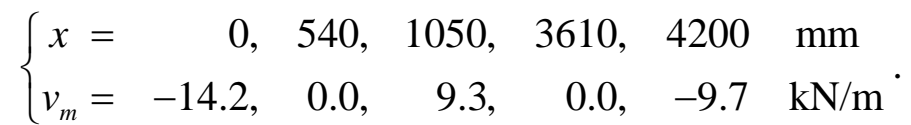

A comparison between the computed shear transfer profiles and those derived using the numerical model in ATENA is shown in Fig. 16. Very good agreement between the computed and predicted shear transfer profiles is observed.

\section{Conclusions}

This paper presents the results of nonlinear finite element analyses of the transverse slip and shear transfer behaviour of bolts in BSP beams. An experimental study of moderately reinforced BSP beams subjected to four-point bending tests was conducted to validate the finite element model. A comprehensive parametric study of the shear transfer profiles in BSP beams with various beam geometries under different loading conditions was conducted. The main findings of this study are summarised as follows. 
(1) Bolt connections in BSP beams can be simulated using discrete bolt elements composed of outer quadrilateral elements simulating the bolt-slip relationship and inner triangular elements simulating the bolt shafts. The numerical results derived from the NLFEA show promising agreement with the experimental results in terms of the overall load-deflection curve and specific shear transfer behaviour. (2) The shear transfer in a BSP beam under point loading is concentrated in the vicinity of the applied load, and the negative shear transfer is concentrated at the supports. The positive and negative shear transfers balance each other and satisfy the vertical bolt force equilibrium requirement.

(3) The half bandwidth of the shear transfer profile and the support-midspan shear transfer ratios are independent of the magnitude of the applied load and the flexural stiffness of the RC beam. The half bandwidth increases with increasing flexural stiffness of the plate and decreases with increasing bolt stiffness. The half bandwidth increases linearly with the fourth root of the plate-bolt stiffness ratio, or in other words, the square root of the depth of the steel plate.

(4) The magnitude of the shear transfer is controlled by the magnitude of the applied load. Because the shear transfer increases drastically when the load level approaches the peak load, a working load level limit of 0.75 should be imposed in the design of BSP beams to avoid excessive bolt shear force demand.

(5) The shear transfer demand decreases significantly as the flexural stiffness of the RC beam increases and increases rapidly as the flexural stiffness of the plate increases. Therefore, the plate-RC stiffness ratio should be limited to ensure an acceptable bolt shear force demand.

(6) The design table and formulae provided in this paper can be used to determine the shear stress transfer profiles of BSP beams subjected to six basic load cases. Under the working load conditions $\left(F / F_{p}<0.5\right)$, the shear transfer profile and hence the critical bolt shear force of BSP beams subjected to complicated external load conditions can be evaluated by superimposing the shear transfer profiles from individual basic load cases.

\section{Acknowledgements}


The research described in this paper received financial support from the Research Grants Council of the Hong Kong SAR (Project No. HKU7151/10E) and The University of Hong Kong through the Small Project Funding 2013, both of which are gratefully acknowledged. 


\section{References}

[1] Hamoush SA, Ahmad SH. Debonding of Steel Plate-Strengthened Concrete Beams. Journal of Structural Engineering 1990;116(2):356-71.

[2] Adhikary BB, Mutsuyoshi H, Sano M. Shear strengthening of reinforced concrete beams using steel plates bonded on beam web: experiments and analysis. Construction and Building Materials 2000;14(5):237-44.

[3] Buyukozturk O, Gunes O, Karaca E. Progress on understanding debonding problems in reinforced concrete and steel members strengthened using FRP composites. Construction and Building Materials 2004;18(1):9-19.

[4] Ebead U, Saeed H. Hybrid shear strengthening system for reinforced concrete beams: An experimental study. Engineering Structures 2013;49:421-33.

[5] Dias SJE, Barros JAO. Performance of reinforced concrete $\mathrm{T}$ beams strengthened in shear with NSM CFRP laminates. Engineering Structures 2010;32(2):373-84.

[6] Roberts TM, Haji-Kazemi H. Strengthening of under-reinforced concrete beams with mechanically attached steel plates. International Journal of Cement Composites and Lightweight Concrete 1989;11(1):21-7.

[7] Su RKL, Zhu Y. Experimental and numerical studies of external steel plate strengthened reinforced concrete coupling beams. Engineering Structures 2005;27(10):1537-50.

[8] Souici A, Berthet JF, Li A, Rahal N. Behaviour of both mechanically connected and bonded steel-concrete composite beams. Engineering Structures 2013;49:11-23.

[9] Foley CM, Buckhouse ER. Method to increase capacity and stiffness of reinforced concrete beams. Practice Periodical on Structural Design and Construction 1999;4(1):36-42.

[10] Subedi NK, Baglin PS. External plate reinforcement for concrete beams. Journal of Structural Engineering 1998;124(12):1490-5.

[11] Siu WH. Flexural Strengthening of Reinforced Concrete Beams by Bolted Side Plates. PhD dissertation. Hong Kong: the University of Hong Kong; 2009.

[12] Su RKL, Siu WH, Smith ST. Effects of bolt-plate arrangements on steel plate strengthened reinforced concrete beams. Engineering Structures 2010;32(6):1769-78. 
[13] Li LZ, Lo SH, Su KL. Experimental study of moderately reinforced concrete beams strengthened with bolted-side steel plates. Advances in Structural Engineering 2013;16(3):499-516.

[14] Smith ST, Bradford MA. Local Buckling of Side-Plated Reinforced-Concrete Beams. II: Experimental Study. Journal of Structural Engineering 1999;125(6):635-43.

[15] Molenstra N, EPPIB, Johnson RP. Partial Shear Connection in Composite Beams for Buildings. ICE Proceedings 1991;91(4):679-704.

[16] Siu WH, Su RKL. Analysis of side-plated reinforced concrete beams with partial interaction. Computers and Concrete 2011;8(1):71-96.

[17] Oehlers DJ, Nguyen NT, Ahmed M, Bradford MA. Transverse and longitudinal partial interaction in composite bolted side-plated reinforced-concrete beams. Structural Engineering and Mechanics 1997;5(5):553-63.

[18] Nguyen NT, Oehlers DJ, Bradford MA. An analytical model for reinforced concrete beams with bolted side plates accounting for longitudinal and transverse partial interaction. International Journal of Solids and Structures 2001;38(38-39):6985-96.

[19] Siu WH, Su RKL. Load-deformation prediction for eccentrically loaded bolt groups by a kinematic hardening approach. Journal of Constructional Steel Research 2009;65(2):436 - 442.

[20] Su RKL, Siu WH. Nonlinear response of bolt groups under in-plane loading. Engineering Structures 2007;29(4):626-34.

[21] Cervenka V, Cervenka J. User’s Manual for ATENA 2D. Prague, Czech Republic: Cervenka Consulting; 2012.

[22] Cervenka V, Cervenka J, Jendele L. ATENA Program Documentation Part 1: Theory. Prague, Czech Republic: Cervenka Consulting; 2012.

[23] Lam WY. Plate-reinforced composite coupling beams: experimental and numerical studies. PhD dissertation. Hong Kong: the University of Hong Kong; 2006.

[24] Kupfer HB, Gerstle KH. Behavior of concrete under biaxial stresses. Journal of the Engineering Mechanics Division 1973;99(4):853-66.

[25] Darwin D, Pecknold DA. Nonlinear biaxial stress-strain law for concrete. Journal of the Engineering Mechanics Division 1977;103(2):229-41. 
[26] Hordijk DA. Local approach to fatigue of concrete. PhD dissertation. the Netherlands: Delft University of Technology; 1991.

[27] CEB. CEB-FIP Model Code 1990; Design Code. London: Comité Euro- International du Béton; 1993.

[28] Van Mier JGM. Multiaxial strain-softening of concrete. Materials and Structures 1986;19(3):179-90.

[29] Hilti. Fastening Technology Manual. Hong Kong: Hilti Corporation; 2011. 


\section{Notations}

$A_{p}$ is the cross-sectional area of the steel plates

$\mathrm{C}_{1}, \mathrm{C}_{2}$, and $\mathrm{C}_{3}$ are constants

$D_{c}$ is the depth of the RC beam

$D_{p}$ is the depth of the steel plates

$E$ is the Young's modulus of the steel

$E_{0}$ is the initial modulus of the concrete

$(E A)_{p}$ is the axial stiffness of the steel plates

$E_{c}, E_{s}$ and $E_{p}$ are the moduli of the concrete, reinforcement, and steel plate materials, respectively

$E_{c c}$ is the secant modulus at the peak compressive strength of the concrete

$(E I)_{C}$ is the flexural stiffness of the RC beam

$(E I)_{p}$ is the flexural stiffness of the steel plates

$F$ is the external point load or the total external load

$F_{1}$ is the external point load

$F_{p}$ is the peak external load

$f_{c}$ is the compressive strength of the concrete

$f_{c}^{e f}$ is the effective compressive strength of the concrete

$f_{c o}$ is the cylinder compressive strength of the concrete

$f_{c u}$ is the cube compressive strength of the concrete

$f_{y p}$ is the yield strength of the steel plates

$f_{y}$ is the yield strength of the steel rebars

$f_{t}^{e f}$ is the effective tensile strength of the concrete

$G_{f}$ is the fracture energy per unit area of a stress-free crack

$i_{p}$ is the radius of gyration of the steel plates

$K_{b}$ is the shear stiffness of the anchor bolts

$k_{m}$ is the stiffness of connecting media

$L$ is the span of the RC beam 
$L_{c d}$ is the band size for the fictitious compression plane model

$M_{u}$ is the ultimate bending moment of the BSP beam

$n_{b}$ is the number of anchor bolts in a shear span

$q$ and $q_{2}$ are the external uniformly distributed loads

$R_{b y}$ is the yield shear force of an anchor bolt

$S_{b}$ is the longitudinal bolt spacing

$S_{b y}$ is the yield shear deformation of the anchor bolts

$S_{l c}$ is the longitudinal slip at the plate-RC interface

$S_{t r}$ is the transverse slip at the plate-RC interface

$S_{t r, \exp }$ is the experimental transverse slip

$S_{t r, n u m}$ is the numerical transverse slip

$V_{m}$ is the transverse bolt shear force

$V_{m, F}$ is the critical bolt shear force in the middle portion of beam span

$V_{m, L S}$ and $V_{m, R S}$ are the bolt shear forces at the left and right supports, respectively

$v_{m}$ is the shear transfer

$v_{m, F}$ is the shear transfer in the middle portion of beam span

$v_{m, L S}$ and $v_{m, R S}$ are the shear transfers at the left and right supports, respectively

$w$ is the half bandwidth of shear transfer from the RC beam to the steel plates

$w_{c}$ is the crack opening in the concrete

$w_{c r}$ is the crack opening in the concrete at complete release of stress

$w_{c d}$ is the plastic displacement for the fictitious compression plane model

$x$ is the position along the beam span measured from the left support

$x_{F}$ is the loading position measured from the left support

$x_{L}$ and $x_{R}$ are the position of the zero shear transfer measured from the left support

$\beta_{p}$ is the flexural stiffness ratio between the steel plates and the RC beam

$\beta_{m}$ is the ratio between the stiffness of the bolt connection and the flexural stiffness of the RC beam

$\gamma_{b}$ is the partial safety factor for the bolt connection 
$\zeta_{E I c}, \zeta_{E I p}$, and $\zeta_{K m}$ are the shear transfer factors due to the variation in $(E I)_{c},(E I)_{p}$, and $k_{m}$, respectively ${\sigma_{c}}^{e f}$ is the effective stress of concrete $\sigma_{c n}$ is the normal stress in the crack

$\varepsilon_{c 0}$ is the strain at the peak compressive stress in the concrete

$\varepsilon_{c d}$ is the ultimate compressive strain of the concrete

$\varepsilon_{c}^{e q}$ is the equivalent uniaxial strain of the concrete

$\varepsilon_{c r}$ is the ultimate tensile strain of the concrete

$\varepsilon_{c t}$ is the strain at the peak tensile stress in concrete

$\xi_{F p}$ is the dimensionless shear transfer ratio

The subscripts ${ }_{1}$ and 2 refer to $F_{1}$ and $q_{2}$, respectively. 


\section{List of tables:}

Table 1 Material properties of reinforcement and steel plates

Table 2 Concrete material properties and strengthening details

Table 3 Comparison of experimental and numerical slips

Table 4 Dimensionless half bandwidth and support-midspan shear transfer ratios

\section{List of figures:}

Fig. 1. Illustration of longitudinal and transverse slips

Fig. 2. The equivalent uniaxial stress-strain curve for concrete

Fig. 3. Simulation of bolt connection: (a) bolt element and bolt connection, (b) simulation of bolt shear test and (c) comparison of bolt shear force-slip curves

Fig. 4. Meshing of specimen P100B450

Fig. 5. Cross sections of specimens: (a) reinforcement, (b) strengthening of P100B300/450 and (c) strengthening of P250B300/450R (dimensions in mm)

Fig. 6. LVDT sets for the measurement of longitudinal and transverse slips

Fig. 7. Comparison of load-deflection curves obtained from the experimental and numerical studies for specimens (a) P100B300 and P250B300R and (b) P100B450 and P250B450R

Fig. 8. Comparison of transverse slip profiles obtained from the experimental and numerical studies for specimens (a) P100B300 and (b) P250B300R

Fig. 9. Reference beam under (a) a midspan point load, (b) an asymmetric point load, (c) two symmetric point loads, (d) a uniformly distributed load, (e) a trapezoidal distributed load and (f) a triangular distributed load (dimensions in mm)

Fig. 10. Variation in the shear transfer profile with the location of (a) an asymmetrical load and (b) two symmetrical loads

Fig. 11. Superposition of the shear transfer profiles for (a) two loads and (b) a uniformly distributed $\operatorname{load}\left(F / F_{p}=0.25\right)$ 
Fig. 12. Variation in the shear transfer base on (a) load level and (b) stiffness of RC, plates and bolt connection

Fig. 13. Variation in normalised shear transfer profiles of a BSP beam under three-point bending based on (a) load level, (b) RC stiffness, (d) plate stiffness and (d) bolt stiffness

Fig. 14. Variation in the half bandwidth of the shear force profile of a BSP beam under three-point bending

Fig. 15. An example of the evaluation of shear transfer profile in a BSP beam (dimensions in mm)

Fig. 16. Comparison between the computed shear transfer profiles and that derived from a numerical model 